\title{
HET ARREST VAN DE ONDERNEMINGSKAMER INZAKE DE JAARREKENING 1976 VAN VAN GELDER
}

\author{
door Mr. Drs. H. Beckman
}

\section{Inleiding}

Op 7 februari 1980 heeft de Ondernemingskamer van het gerechtshof te Amsterdam (OK) uitspraak gedaan inzake de door SOBI ingestelde vordering tot herziening van de jaarrekening 1976 van Van Gelder.

In deze procedure kwamen zowel formele als materiële aspecten aan de orde. Met formele aspecten doel ik op de vormvoorschriften van titel 6 boek $2 \mathrm{BW}$. Het gaat hierbij niet alleen om de wijze van presentatie, maar ook om de wettelijke minimumvoorschriften. Met materiële aspecten doel ik op de interpretatieve voorschriften van deze titel. Gedacht kan hierbij worden aan de aanvaardbaarheid van bepaalde waarderingsvoorschriften, maar ook aan de eventueel noodzakelijk te achten toelichtingen op grond van de doelbepaling van de jaarrekening (art. 2: $308 \mathrm{BW}$ ). De grens tussen beide groepen voorschriften is niet altijd scherp te trekken.

De voornaamste onderwerpen die in dit arrest de revue passeren zijn:

- Toelichting als één geheel

- Afwaardering activa

- Herwaardering en daarmee samenhangende reserves

- Samenstelling van het (enkelvoudige) resultaat

- Latente belastingverplichtingen

- Actieve belastinglatenties.

\section{Toelichting als een geheel}

De jaarrekening van Van Gelder bevat de volgende presentatievolgorde: geconsolideerde balans, geconsolideerde winst- en verliesrekening, toelichting, balans en winst en verliesrekening. Onder de toelichting is opgenomen een kleine passage Algemeen, een Toelichting op de balansposten en Enige gegevens omtrent de commissarissenbeloning.

Bij deze presentatiewijze valt op dat een onderdeel van de toelichting op de vennootschappelijke jaarrekening voorop wordt gesteld en dat een toelichting op de enkelvoudige balans, een toelichting op enkelvoudige winst- en verlies. rekening en een toelichting op de geconsolideerde winst- en verliesrekening ontbreken. Op deze punten makkt eiseres bezwaren.

Het oordeel van de OK is zeer duidelijk. Het wettelijk systeem is aldus dat de jaarrekening als één geheel dient te worden opgemaakt, vastgesteld en goedgekeurd. Afzonderlijke toelichtingen schrijft de wet niet dwingend voor.

Voor Van Gelder betekent de zienswijze van de OK dat de presentatievolg. orde wordt aanvaard, daar bij concernverhoudingen bij die presentatiewijze geen afbreuk aan het inzicht dat art. 2: $308 \mathrm{BW}$ eist, wordt gedaan, alsmede dat bij de gekozen presentatievolgorde het niet noodzakelijk is afzonderlijke 
toelichtingen op de enkelvoudige cijfers te geven. Aan dit laatste voegt de OK evenwel een belangrijke passage toe n.l. „Of de jaarrekening naar haar inhoud aan de bepalingen der wet voldoet is een andere vraag (...).

Bij de constatering van de OK dat de toelichting als één geheel moet worden gezien, past ook de zienswijze dat vermeldingen in het bestuursverslag, die in de jaarrekening behoren te staan, ten onrechte in het bestuursverslag worden vermeld. Ook verwijzingen in de jaarrekening naar die vermeldingen, maken deze vermeldingen niet tot onderdeel van de jaarrekening. Dit laatste komt bij Van Gelder voor. In de jaarrekening wordt voor een nadere toelichting op de toegepaste waarderingsgrondslagen naar het bestuursverslag verwezen. De OK heeft daarom op dit punt aan Van Gelder een aanwijzing gegeven. Op grond van de wet ( art. 2: $137 \mathrm{BW}$ ) dient als het bestuursverslag schriftelijk wordt uitgebracht, dit verslag gescheiden van de jaarrekening te worden gehouden. Daarnaast noem ik nog een ander argument. Een jaarrekening kan ook in omloop komen los van het bestuursverslag; ook voor de wettelijke de. poneringsplicht van de jaarrekening bij het handelsregister geldt niet dat het bestuursverslag moet worden neergelegd.

\section{Inhoudelijke toetsing}

De OK scheidt in haar beoordeling het presentatie-aspect van het inhoudelijke aspect. Bij haar zienswijze omtrent de presentatie abstraheert zij a.h.w. van de inhoudelijke vermeldingen. Bij de inhoudelijke toetsing past de OK bovendien een kunstgreep toe. De passages omtrent de waarderingsgrondslagen in het bestuursverslag worden voor de inhoudelijke beoordeling geacht te behoren tot de jaarrekening.

Eiseres voert als bezwaar aan dat in de toelichting ten onrechte de grond. slagen waarop de herwaardering van de activa berust niet zijn vermeld en toegelicht. Eiseres noemt met name dat niet vermeld is of toetsing aan de directe dan wel indirecte opbrengstwaarde heeft plaatsgevonden. In de betrokken passages van het bestuursverslag wordt hierover wel de noodzakelijke duidelijkheid gegeven.

De OK verwerpt de bezwaren van eiseres omdat de betrokken passages ge. acht worden te behoren tot de jaarrekening. Ik meen dat de opvatting van de OK in dit verband onjuist is. De bedoelde passages behoren nu eenmaal niet tot de jaarrekening en kunnen om die reden voor de inhoudelijke beoordeling niet geacht worden te behoren tot de jaarrekening. Ik verwijs naar mijn eerdere opmerking dat de jaarrekening ook los van het bestuursverslag kan worden openbaar gemaakt.

De opvatting van de OK omtrent de inhoudelijke toetsing spreekt wel aan voor zover het om de jaarrekening zelf gaat. Door in de toelichting op de ge. consolideerde balans op te nemen dat de waarderingsgrondslagen ook voor de (enkelvoudige) balans gelden, wordt een onnodige doublure vermeden. Dit geldt ook voor de geconsolideerde winst- en verliesrekening. In het onderhavige geval waren de grondslagen van de bepaling van het resultaat niet vermeld, zodat inhoudelijke toetsing tot een aanwijziging moest leiden. In dit verband verdient stellig de aandacht de volgende overweging van de OK: dat het voor het inzicht dat de jaarrekening dient te geven in het al- 
gemeen noodzakelijk is dat de (. . .) uiteenzettingen (omtrent waardering en bepaling van het resultaat) afzonderlijk in de toelichting worden gepresenteerd en dat ieder van deze uiteenzettingen een volledige uiteenzetting geeft onderscheidenlijk omtrent de toegepaste waarderingsgrondslagen (...) en omtrent de resultatenbepaling".

Ook al behoeft gezien de presentatie bij Van Gelder op de enkelvoudige stukken geen afzonderlijke toelichting te worden gegeven dan houdt dit niet in dat de wettelijke minimumvoorschriften buiten beschouwing mogen blij. ven. Van Gelder houdt hieromtrent een uitvoerig pleidooi. $\mathrm{Zij}$ voert onder meer aan dat de bijzondere bepalingen niet nageleefd behoeven te worden in. dien afbreuk wordt gedaan aan het algemene beginsel van art. 2: $308 \mathrm{BW}$. Dit pleidooi moest gezien de wetshistorie en wetssystematiek bij voorbaat falen').

Bovendien draait Van Gelder de zaak om. De bijzondere bepalingen zijn een uitvloeisel van art. 2: $308 \mathrm{BW}$ en dienen derhalve tot ondersteuning van het in art. 2: 208 BW bedoelde inzicht. Zodra de vierde EG-richtlijn inzake de jaarrekening in ons recht is opgenomen, kan dit enigszins anders komen te liggen. De richtlijn sluit de mogelijkheid niet uit dat toepassing van een bepaling van de richtlijn in uitzonderingsgevallen in strijd is met de doelbepaling van de jaar. rekening. Alsdan dient de afwijking te worden vermeld, met aangeving van de redenen en de invloed op het vermogen, de financiële positie en het resul. taat. Zie hierover ook art. 362 van het wetsontwerp aanpassing vierde richtlijn dat op 8 september j.l. bij de Tweede Kamer is ingediend.

Voor de concrete verslaggevingspraktijk houdt de zienswijze van de OK in dat, indien geen afzonderlijke toelichtingen op de enkelvoudige stukken worden verstrekt, in ieder geval in de toelichting op de geconsolideerde stukken ook de wettelijk voorgeschreven specificaties met betrekking tot de enkelvou. dige posten moeten worden opgenomen. Zo is bij Van Gelder ten onrechte niet vermeld wat de omvang van de (enkelvoudige) voorziening voor latente belastingen is (zie hierna ook onder VII). Ook is ten onrechte geen mutatie. overzicht onderscheiden naar herkomst met betrekking tot de (enkelvoudige) reserves opgenomen (zie hierna ook onder V). Een aantal gegevens omtrent de (enkelvoudige) voorziening voor reorganisatiekosten ontbreekt eveneens in de jaarrekening (zie hierna ook onder IV).

\section{Afwaardering activa}

Van Gelder heeft in $1970 f 120$ miljoen toegevoegd aan de voorziening voor reorganisatiekosten. Deze voorziening is ten dele ten laste van de herwaarde. ringsreserve ( 67 miljoen) en ten dele ten laste van de winstreserves gevormd. Ter motivering van de vorming is toendertijd onder meer in het bestuursver. slag opgemerkt dat rekening moet worden gehouden met de omstandigheid dat een aantal vaste activa moet worden afgeboekt op een moment dat hun boekwaarde nog belangrijk hoger is dan de restwaarde in verband met struc-

\footnotetext{
1) Van Gelder voert ook aan: „Het concern bestaat immers weliswaar formeel-juridisch uit de moedermaatschappij en een aantal dochters-rechtspersonen, doch commercieel, administratief en economisch is het concern volledig geïntegreerd, wordt aan de juridische structuur voorbijgegaan en is slechts de divisiestructuur van belang, die dwars door de juridische structuur loopt ... De OK stelt hiertegenover: .... . De wet verbindt nu eenmaal gevolgen aan de juridische structurur (...) Daaraan kan een moedermaatschappij zich niet ontrekken op grond dat bij een andere aan de bedrijfseconomische struc. tuur aangepaste juridische structuur de (enkelvoudigel balans slechts uit enkele posten zou hebben kunnen bestaan."
} 
turele veranderingen in de papierindustrie. De daaruit voortvloeiende reorganisatie zal bovendien aanzienlijke kosten met zich meebrengen.

In onder meer het verslagjaar 1976 hebben afboekingen op de boekwaar. den van de vaste activa plaatsgevonden. Deze afboekingen zijn noch ten laste van het resultaat noch ten laste van de herwaarderingsreserve geboekt. De af. boekingen hebben plaatsgevonden ten laste van de voorziening voor latente belastingen en ten laste van de voorziening voor reorganisatiekosten. Het eer. ste blijkt overigens niet uit de jaarrekening.

Eiseres voert tegen de toegepaste afwaarderingen een aantal bezwaren aan. $\mathrm{Zij}$ meent dat moet worden meegedeeld:

- waarom activa zijn afgewaardeerd

- welke activa zijn afgewaardeerd

- de omvang van de herwaardering, enkelvoudig en geconsolideerd

- hoeveel is onttrokken aan de herwaardering en hoeveel aan de voorziening voor latente belastingen

- waarom de afboeking niet ten laste van het resultaat is geschied.

$\mathrm{De} \mathrm{OK}$, die van de relevante passages uit het bestuursverslag aanneemt dat zij tot de jaarrekening behoren, is van oordeel dat voldoende duidelijk is welke activa zijn afgewaardeerd, waarom is afgewaardeerd en dat de afwaardering ten laste van de voorziening voor reorganisatie is geschied. Uit het bestuursverslag blijkt onder meer dat het gaat om bedrijfsonderdelen, waarvan het voortbestaan hoogst onzeker is, dat deze zijn gewaardeerd op netto-opbrengstwaarde en dat de afboeking ten laste van de voorziening voor reorganisatie heeft plaatsgevonden. Uit de jaarrekening blijkt nog dat voor deze bedrijfson. derdelen op korte termijn herstructureringsmaatregelen noodzakelijk zijn.

De OK is wel van oordeel dat gezien art. 2: $308 \mathrm{BW}$ ten onrechte het totale bedrag van de afwaarderingen niet vermeld wordt. Uit de processtukken blijkt dat het om circa $f 32.000 .000,-$ gaat. Uit de toelichting op de jaarrekening blijkt een onttrekking aan de voorziening voor reorganisatie voor afwaardering en overige reorganisatiekosten ter grootte van $f$ 18.637.480,-- Naast de overige reorganisatiekosten blijkt nog een post in dit bedrag te zijn begrepen, die niets uitstaande heeft met de afwaardering. Er heeft namelijk nog een overboeking van $f$ 4,3 miljoen naar de rekening herwaardering plaatsgevonden.

Samenvattend kan gesteld worden dat de OK verlangt dat de omvang van de extra afboeking in verband met herstructureringsmaatregelen vermeld moet worden en dat aangegeven moet worden ten laste waarvan de afboekingen geschieden.

Op de vordering van eiseres dat aangegeven moet worden, waarom de afboeking niet ten laste van het resultaat heeft plaatsgevonden, wordt door de OK niet expliciet ingegaan. Hetgeen Van Gelder betoogt wordt kennelijk overgenomen n.l. "de afwaardering is niet ten laste van het resultaat gebracht omdat daarvoor een voorziening is getroffen". In het licht van wat ik in de aanvang van deze paragraaf vermeldde is de afboeking ten laste van de voorziening voor reorganisatiekosten ten dele wel logisch, daar deze voorziening gedeeltelijk gevoed is uit de herwaarderingsreserve. In die tijd werd de herwaardering van vaste activa nog voor $100 \%$ aan de herwaarderingsreserve toegevoegd. De afboeking van de boekwaarde van de vaste activa, voor zover sa- 
menhangend met in het verleden plaatsgevonden herwaarderingen zal daar. om ten laste van deze voorziening gebracht moeten worden. Afboekingen be neden de fiscale boekwaarden leiden tevens tot belastingverminderingen, welke daarom moeten leiden tot een vermindering van de voorziening voor la. tente belastingen.

\section{v. Herwaardering en daarmede samenhangende reserves}

Uit de jaarrekening van Van Gelder kan het volgende overzicht van de reser. ves in de balans worden samengesteld:

\begin{tabular}{|c|c|c|c|c|}
\hline & \multicolumn{2}{|l|}{ Enkelvoudig } & \multicolumn{2}{|l|}{ Geconsolideerd } \\
\hline & 1976 & 1975 & 1976 & 1975 \\
\hline & $f$ & $f$ & $f$ & $f$ \\
\hline \multirow{3}{*}{$\begin{array}{l}\text { Herwaardering } \\
\text { duurzame activa } \\
\text { Herwaarderingsre- } \\
\text { serve voorraden } \\
\text { Reserve deelne- } \\
\text { mingen }\end{array}$} & 92.610 .572 & 82.799 .322 & 149.861 .334 & 145.569 .727 \\
\hline & 21.864 .586 & 21.799 .186 & 43.123 .447 & 45.983 .117 \\
\hline & 88.848 .438 & 98.346 .399 & 518.233 & 518.233 \\
\hline \multirow{3}{*}{ Geacc. resultaten } & 203.323 .596 & 202.944 .907 & 193.503 .014 & 192.071 .077 \\
\hline &.$/ .23 .305 .142$ & 13.376 .690 &.$/ .13 .484 .560$ & 24.250 .520 \\
\hline & 180.018 .454 & 216.321 .597 & 180.018 .454 & 216.321 .597 \\
\hline
\end{tabular}

Eiseres heeft problemen met het verschil van $f$ 9.820.582,- tussen de geconsolideerde omvang van $f$ 193.503.014,- en de enkelvoudige omvang van $f$ 203.323.596,-. Zij begrijpt ook niet hoe de herwaarderingsreserve van duurzame activa met $f 9.811 .250$,- in de enkelvoudige balans kan stijgen, terwijl deze reserve in de geconsolideerde balans met $f$ 4.291.607,- stijgt.

Gedaagde stelt hiertegenover dat in het verleden circa $f$ 4,3 miljoen teveel van de herwaardering is overgebracht naar de voorziening voor reorganisatie en dat deze teveelpost thans is teruggeboekt. Tevens blijkt een post van circa $f$ 5,6 miljoen inzake latente belasting over de herwaardering bij een dochteronderneming in 1975 bij die dochter niet te zijn geboekt, maar wel bij Van Gelder. Voorts vermeldt Van Gelder nog dat uit de vergelijking van de enkelvoudige en geconsolideerde geaccumuleerde resultaten blijkt dat het geaccumuleerde resultaat van deelnemingen $f 9.820 .582,-$ bedraagt. De verschillen zijn derhalve afdoende verklaard.

De OK acht de toegepaste correcties aanvaardbaar, maar acht de toelichting op die posten ontoereikend. Zij moeten afzonderlijk worden vermeld en toegelicht, te meer nu de passage uit het bestuursverslag de indruk wekt dat geen mutatie in de reserve herwaardering heeft plaatsgevonden. 


\section{Samenstelling enkelvoudig resultaat}

Eiseres is van oordeel dat Van Gelder de (enkelvoudige) winst- en verliesreke ning ten onrechte laat bestaan uit één regel, te weten netto-resultaat. Zij meent dat afzonderlijk vermeld dient te worden het resultaat van Van Gelder (exclu. sief geconsolideerde deelnemingen) en het resultaat van geconsolideerde deelnemingen. Van Gelder voert o.a. als verweer aan dat het resultaat ingevolge art. 2: 336 BW niet gesplitst behoeft te worden.

De OK wijst de vordering van eiseres af met een beroep op de wetshistorie. Het door de OK citaat uit de MvT luidt als volgt

„Deze (eigen) cijfers nu geven dikwijls weinig inlichtingen van betekenis naast de geconsolideerde cijfers; wanneer de onderneming een zuivere holdingmaatschappij is, zijn de posten op haar winst- en verliesrekening zelfs niets anders dan een optelsom van de bedragen der afzonderlijke deelne. mingen. Vandaar dat er aanleiding toe bestaat de onderneming te ontheffen van de verplichting tot het specificeren van haar eigen winst- en verliesrekening wanneer in de geconsolideerde rekening - zelfs wanneer de consolidatie niet het gehele concern betreft - de vereiste posten van de in de consolidatie opgenomen maatschappijen voorkomen."

Artikel 402 van het wetsontwerp aanpassing vierde EG-richtlijn verlangt in ieder geval dat het resultaat uit deelnemingen afzonderlijk moet worden ver. meld.

\section{Latente belastingverplichtingen}

In de jaarrekening vermeldt Van Gelder de omvang van de geconsolideerde voorziening voor latente belastingverplichtingen. De enkelvoudige omvang wordt niet vermeld. Eiseres verlangt daarom met beroep op de wetsvoorschriften dat alsnog de enkelvoudige omvang wordt vermeld.

Gedaagde acht het standpunt van eiseres formeel juist, maar meent dat de afzonderlijke vermelding niet bevorderlijk is voor het inzicht dat de jaarrekening dient te geven. Zij merkt nog op dat bij geconsolideerde deelnemingen die niet tot de fiscale eenheid behoren, de latente belastingvoorziening bij die deelnemingen wordt gevormd en dat bij geconsolideerde deelnemingen die wel tot de fiscale eenheid behoren de latente belastingvoorziening bij de moeder wordt gevormd. De geconsolideerde balans omvat derhalve de belasting. latenties van alle deelnemingen.

Uit hetgeen de accountant ten processe meedeelt, blijkt dat het weinig moeite moet hebben gekost om de omvang van de latente belastingverplichtingen van de fiscale eenheid in de (enkelvoudige) balans te vermelden. Hierbij kan men zich afvragen of de vermelding van de latente belastingverplichtingen van de fiscale eenheid beantwoordt aan de eis dat de (enkelvoudige) omvang van de voorziening voor latente belastingvoorzieningen moet worden ver. strekt.

De OK constateert dat de voorziening voor latente belastingen ook in de (en. kelvoudige) balans of toelichting moet worden vermeld. Op het door Van Gel. der aangevoerde dat het bij een fiscale eenheid een moeilijke zaak is de enkelvoudige omvang van de latente belastingverplichtingen te vermelden, aangezien de toerekening daarvan aan de juridische onderdelen in velerlei opzicht 
een arbitraire zaak is, wordt door de OK niet ingegaan. De OK vermeldt „het door Van Gelder aangevoerde doet daaraan niet af". De conclusie kan slechts zijn dat de OK de enkelvoudige omvang bedoelt, zonder acht te slaan op de problemen inzake toerekening.

Ik meen dat de OK terecht voorbij gaat aan het arbitraire vraagstuk van de toerekening aan de juridische onderdelen. Het is zeer wel mogelijk om de voor. ziening voor latente belastingverplichtingen, exclusief de voorziening voor de latente belasting voor de overige tot de fiscale eenheid behorende deelnemin. gen te tonen. Men dient de voorziening te tonen als ware er geen fiscale eenheid. Toerekeningsvraagstukken zijn in dit verband nauwelijks arbitrair te noemen. Wel kan men zich afvragen wat de zin is van het vermelden van de enkelvoudige omvang, te meer daar Van Gelder (met de tot de fiscale eenheid behorende deelnemingen) voor de belastingschulden van de fiscale eenheid hoofdelijk aansprakelijk is. Toerekeningsproblemen kunnen overigens wel ontstaan als actieve belastinglatenties in het geding zijn.

\section{Actieve belastinglatenties}

Alvorens op de actieve latenties in te gaan schets ik in het kort de hoofdlijnen van het door Van Gelder toegepaste systeem van verantwoording van belas. tinglasten en van belastinglatenties. Hierbij zij aangetekend dat het om een veelvuldig toegepast systeem gaat. Van Gelder geeft omtrent de toepassing van dit systeem een duidelijke uiteenzetting in de jaarrekening.

Van Gelder verantwoordt in de winst- en verliesrekening als belastinglast $48 \%$ van het bedrijfseconomisch resultaat, rekening houdend met definitieve verschillen tussen de bedrijfseconomische winst en de fiscale winst, zoals die uit hoofde van de investeringsaftrek. In verliesjaren wordt dientengevolge een belastingbate van $48 \%$ over het verlies verantwoord. Het verschil met de verschuldigde belastingen (bij fiscale winst) of de te vorderen belastingen (bij fis. caal verlies) wordt onttrokken of toegevoegd aan de voorziening voor latente belastingen. De voorziening voor latente belastingen wordt mede gevoed uit de herwaarderingsreserve. Van de totale herwaardering wordt $48 \%$ aan de voorziening voor latente belastingen toegevoegd.

De consequentie van het systeem is dat als de commerciële afschrijvingen hoger zijn dan de fiscale afschrijvingen, zoals bij Van Gelder de voorziening voor latente belastingverplichtingen afneemt en wel met $48 \%$ van het afschrij. vingsverschil. Deze afneming leidt tot een dienovereenkomstig hogere belas. tingschuld aannemende dat het verschil tussen het bedrijfseconomisch resul. taat en het fiscaal resultaat gelijk is aan het afschrijvingsverschil. Is het bedrijfseconomisch reultaat negatief, evenals het fiscaal resultaat, dan leidt de afneming van de belastingvoorziening tot een belastingbate en wel ter grootte van $48 \%$ van het afschrijvingsverschil.

Een andere consequentie van het systeem is dat als sprake is van een fiscaal verlies een vordering op de fiscus ontstaat voor zover achterwaartse verlies. compensatie mogelijk is. Deze vordering behoeft op grond van de wetsvoorschriften gewoonlijk niet afzonderlijk vermeld te worden en zal bij aanwezig. heid van nog openstaande belastingschulden met deze schulden worden gesaldeerd. Is achterwaartse verliescompensatie niet of slechts ten dele mogelijk 
dan ontstaat een voorwaardelijke „vordering” op de fiscus. Deze actieve latentie wordt, indien aannemelijk is dat realisatie binnen de carry forward periode mogelijk is met de voorziening voor latente belastingverplichtingen gesal. deerd.

Uit de jaarrekening van Van Gelder blijkt dat het bedrijfseconomisch resul taat negatief is. De daarmee samenhangende belastingbate wordt ten processe als volgt gespecificeerd:

1. Vrijgevallen voorziening contante betaling

2. Carry-back met 1974

3. Afname latentie vaste activa door afschrijvingsverschil len over 1976

4. Toename latentie op voorraden

5. Carry-forward

6. Belastinglast buiten fiscale eenheid

Belastingbate

Tegen het door Van Gelder toegepaste systeem is door eiseres een aantal be. zwaren gemaakt. Voor zover van belang hebben deze bezwaren betrekking op de volgende punten:

a. de belastingbate uit hoofde van het afschrijvingsverschil;

b. de actieve belastinglatentie uit hoofde van voorwaartse verliescompensatie;

c. de toelichting op de post belastingbaten in de jaarrekening.

Ad a. Belastingbate uit hoofde van het afschrijvingsverschil.

Eiseres is van oordeel dat de vrijval aan latente belastingen uit hoofde van het afschrijvingsverschil tussen de commerciële en fiscale afschrijvingen niet ten gunste van het resultaat mag vrijvallen, voor zover de belastinglatentie is ontstaan als gevolg van herwaardering. Eiseres motiveert deze zienswijze door te stellen dat de voorziening voor latente belastingen, voor zover samenhangend met het toepassen van vervangingswaarde is gevormd ten laste van het vermogen. Een vrijval kan daarom nooit ten gunste van het resultaat plaatsvinden. Dit bedrag dient aan het eigen vermogen te worden toegevoegd.

Gedaagde stelt hier tegenover dat het door haar toegepaste systeem zou fa. len bij toevoeging van de vrijval aan de herwaarderingsreserve, indien op ver. liesjaren weer winstjaren volgen. Er zal dan meer belasting betaald moeten worden. Het toegepaste systeem is in feite de noodzakelijke consequentie van het in beginsel aanvaarden van de opsplitsing van de herwaardering in een voor de fiscus wel en in een voor de fiscus niet aanvaardbaar deel.

De OK is van oordeel dat het systeem van Van Gelder niet in de weg staat aan het inzicht dat de jaarrekening dient te geven, mits duidelijk toegelicht. Het toegepaste systeem leidt er niet toe dat de materiële activa voor $100 \%$ in stand 
worden gehouden. Een keuze voor een dergelijke beperkte substantiehandhaving staat een onderneming vrij.

In de onderhavige situatie acht de OK het systeem in zijn consequenties voor het vermogen en het resultaat duidelijk toegelicht.

\section{Ad $b$. Actieve belastinglatenties.}

Zoals opgemerkt vloeit uit het systeem van Van Gelder voort dat met „,belas tingvorderingen" uit hoofde van voorwaartse verliescompensatie rekening wordt gehouden. Eiseres acht dit onjuist onder meer omdat carry forward nooit tot een vordering op de fiscus leidt, ook niet tot een voorwaardelijke. Men krijgt geen geld terug, maar men wordt alleen ontslagen van anders opgelegde belastingaanslagen. Het voordeel uit hoofde van carry forward ontstaat pas als in de komende jaren fiscale winst wordt genoten.

Gedaagde merkt onder meer op dat als binnen de wettelijke termijn van carry forward voldoende bijtellingen op het fiscale resultaat mogelijk zijn, waarvoor een toereikende latente belastingvoorziening beschikbaar is, actieve be lastinglatenties geactiveerd kunnen worden. Bij het door Van Gelder toegepaste systeem gaat het om de zekerheid dat - ongeacht of in de compensatieperiode al dan niet fiscale winst wordt gemaakt - latente belastingverplichtingen zullen vervallen, die in het verleden zijn ontstaan en waarvoor een - nu vrijvallende - voorziening bestaat.

De accountant van Van Gelder geeft in een uitvoerig betoog zijn zienswijze op de onderhavige kwestie weer. Hij merkt op dat in het algemeen niet met zekerheid valt te voorspellen of een onderneming gedurende de carry forward periode voldoende winst zal maken om het te activeren bedrag te kunnen compenseren. Het voorzichtigheidsbeginsel zal alsdan dwingen tot afwijking van het matching-beginsel. In het Van Gelder-systeem is er echter één zekerheid ten aanzien van de compensatieperiode. In deze periode zal jaarlijks vrijkomen uit de latente belastingvoorziening $48 \%$ van het surplus aan commerciële afschrijvingen boven de fiscale. De accountant stelt daarom dat als $48 \%$ van het in de toekomst te compenseren verlies gelijk zou zijn aan $48 \%$ van het bedrag van de binnen de carry forward periode vervallende afschrijvingsverschillen de zekerheid aanwezig is dat gecompenseerd wordt en dat derhalve de actieve latentie in aanmerking kan worden genomen.

De OK verwerpt het betoog van Van Gelder en van de accountant. Zij overweegt:

„... dat - zoal aan het recht op voorwaartse fiscale verliescompensatie een waarde zou kunnen worden toegekend - het opnemen van die waarde als bate in het jaar waarin het betreffende verlies is geleden, in de zorgelijke situatie waarin Van Gelder verkeerde, zoals ook in het verslag van de raad van bestuur tot uitdrukking is gebracht, in strijd is met de voorzichtigheid. Dit klemt temeer nu het systeem inhoudt dat de voorziening voor latente belastingen in volgende jaren, waarin weer winst wordt gemaakt, weer ten laste van de winst - en verliesrekening moet worden aangevuld. Aldus wordt in het heden een bate geboekt die in de toekomst tot lastenverzwaring leidt $\ldots$...

De laatste volzin uit het zojuist weergegeven citaat van de OK is m.i. onjuist. De omvang van de voorziening voor latente belastingen dient getrouw te wor- 
den weergegeven. Zo deze voorziening in de toekomst toeneemt, hangt dit samen met toekomstige afwijkingen tussen de commerciële en fiscale resultaten en tussen het commercieel en fiscaal vermogen. Er is geen sprake van het boe. ken van een bate in het heden die tot belastingverzwaring in de toekomst leidt. Hiervan kan alleen sprake zijn indien men de zienswijze huldigt dat fiscale grondslagen bepalend zijn voor de verantwoording van de belastingpost in de winst- en verliesrekening. Deze dienswijze is - naar ik meen onjuist omdat deze niet in overeenstemming is met normen die in het maatschappelijk verkeer als aanvaardbaar worden beschouwd.

Voor het afwijzend oordeel van de $\mathrm{OK}$ in de onderhavige casus heb ik wel begrip. Van Gelder zoekt de zekerheid omtrent de mogelijkheden van het in aanmerking nemen van actieve belastinglatenties in de toekomstige afschrijvingsverschillen. Deze afschrijvingsverschillen hangen samen enerzijds met het toepassen van vervangingswaarde anderzijds met de verschillen in com merciële en fiscale afschrijvingspercentages. Slechts in het laatste geval kan van de vereiste zekerheid sprake zijn. Maakt men in de toekomst weer winst, dan zal een deel van de belastinglatenties omgezet worden in belastingschuld. Deze belastingschuld kan gecompenseerd worden met de actieve latentie tot het einde van de carry forward periode. Maakt men verlies dan wordt een deel van de belastinglatenties niet omgezet in schuld, maar valt vrij.

De vereiste zekerheid ontbreekt voor zover het afschrijvingsverschil ontstaat als gevolg van het toepassen van vervangingswaarde. De voorwaarde voor het in aanmerking nemen van actieve latenties is dat de continuiteit gewaarborgd moet zijn. De OK twijfelt daaraan gezien de verwijzing naar de zorgelijke situatie van Van Gelder. Deze twijfel kan de verwachting meebrengen dat de toegepaste waarderingsgrondslagen niet langer juist zijn waardoor de omvang van én de herwaarderingsreserve én de voorziening voor latente belastingen kan worden aangetast. Ook afgezien hiervan, kan de vervangingswaarde in de toekomst dalen waardoor eveneens de omvang van de herwaarderingsreserve en de omvang van de voorziening voor latente belastingen kunnen dalen. Deze overwegingen verhinderen in afdoende mate de mogelijkheid om passieve la. tenties, samenhangend met herwaardering als compensatiemiddel voor actieve latenties in aanmerking te nemen.

Ik acht het niet uitgesloten dat als Van Gelder een duidelijke scheiding zou hebben gemaakt tussen vrijval van belastinglatenties uit hoofde van tijdelijke verschillen en die uit hoofde van herwaardering dit de kans op acceptatie dat actieve belastinglatenties uit hoofde van voorwaartse verliescompensatie in aanmerking moeten worden genomen, aanzienlijk vergroot had, mits de passieve latenties uit hoofde van herwaardering niet als compensatiemiddel worden gebruikt. De realisatie van de actieve latenties is in die omstandigheid afdoende gewaarborgd.

Ad c. Toelichting op de post belastingen.

Eiseres is van oordeel dat de toelichting op de post belastingen ontoereikend is. $\mathrm{Zij}$ meent dat de ten processe verstrekte specificatie van de belastingbate in de jaarrekening had behoren te worden vermeld.

Gedaagde stelt hier tegenover dat een dergelijke specificatie in de jaarreke. ning overbodig is. Een te grote detaillering kan het verantwoorde oordeel belemmeren. 
De OK is van oordeel dat de in aanmerking genomen bedragen uit hoofde van carry back en uit hoofde van het afschrijvingsverschil afzonderlijk in de toelichting behoren te worden opgenomen. Het ontbreken van een specificatie en een (beknopte) toelichting daarop maken niet duidelijk welke factoren bij de berekening van de belastingen in aanmerking worden genomen en doet de jaarrekening niet het vereiste inzicht geven. De OK laat hierbij de bate uit hoofde van carry forward buiten beschouwing omdat zij van oordeel is dat dit bedrag ten onrechte ten gunste van het resultaat is gebracht.

Wat de bate uit hoofde van carry back betreft, is de OK van oordeel dat dit bedrag niet behoort tot de post ,belastingen met betrekking tot de winst”. Tot deze post behoort wel de belastingbate samenhangend met het afschrijvings verschil. Dit bedrag moet wel worden vermeld en toegelicht, gezien de aan zienlijke invloed in het onderhavige verliesjaar op het uiteindelijke resultaat.

De stelligheid, waarmee de OK aanneemt dat een bate uit hoofde van carry back niet behoort tot het geschatte bedrag vóór belastingen met betrekking tot de winst is naar mijn mening wel juist, maar in andere zin dan de OK bedoelt. De carry back-vordering wordt niet berekend op basis van het verantwoorde bedrijfseconomische resultaat en kan dus om die reden niet behoren tot de post „belastingen met betrekking tot de winst”. Deze laatste post wordt berekend op basis van het bedrijfseconomische resultaat. Is dit resultaat negatief, dan zal een belastingbate worden verantwoord. Aan die bate-verantwoording moet als eis worden gesteld dat ook sprake is van realisatie. Aan die eis kan op verschillende manieren worden voldaan, bijvoorbeeld door vrijval van pas. sieve latenties, door het ontstaan van vorderingen op de fiscus of door de ze kerheid dat in de toekomst vorderingen op de fiscus ontstaan. De laatst bedoelde zekerheid kan slechts aanwezig zijn op grond van reeds bestaande oorzaken. Daarvan is sprake indien in de toekomst latenties actueel worden, maar niet indien men in de toekomst latenties actueel kan maken.

De motivering van de OK dat de belastingbate uit hoofde van het afschrij. vingsverschil afzonderlijk moet worden vermeld en toegelicht is m.i. niet sterk. De vrijval uit hoofde van het afschrijvingsverschil geldt evenzeer in winstjaren. Die vrijval leidt weliswaar niet tot een belastingbate maar tot een belasting. schuld. Dit kan evenwel een aanzienlijke invloed op de in de winst- en verlies. rekening verantwoorde belastinglast hebben.

\section{Afsluitende opmerkingen}

Het arrest toont aan dat de jaarrekening van Van Gelder op een aantal aspecten stellig niet voldoet aan hetgeen titel 6 boek 2 BW eist. Het arrest laat ook zien dat op sommige punten de OK een eigen visie aanhoudt die afwijkt van de in Nederland gangbare opvattingen. Ik doel hier in het bijzonder op:

- de afzonderlijke vermelding van de vrijval van belastinglatenties uit hoofde van afschrijvingsverschillen

- de afzonderlijke vermelding van belastingbaten uit hoofde van carry back

- het niet toelaten van actieve latenties. ${ }^{2}$ )

\footnotetext{
2) Zie evenwel het arrest van de Hoge Raad inzake Pakhoed van 26 maart 1980 en de daarop gebaseerde uitspraak van de OK van 29 mei 1980.
} 
De aanwijzingen van de OK op deze punten mogen niet ten nadele van Van Gelder of diens accountant worden uitgelegd.

De aanwijzingen die de OK aan Van Gelder geeft, beperkt zij tot toekomstige jaarrekeningen. Hierbij neemt zij in aanmerking dat de jaarrekeningen over 1977 en 1978 reeds zijn vastgesteld en gepubliceerd. De jaarrekening 1979 dient met inachtneming van de aanwijzingen te worden opgesteld. $\left.{ }^{3}\right)$

3) Tegen de jaarrekening 1979 is opnieuw een jaarrekeningprocedure aangespannen, zij hec op een andere grond dan in de onderhavige uitspraak 